\title{
Malignant haemangioendothelioma involving the liver
}

\author{
STELLA M. POLLARD ${ }^{1}$ AND G. H. MILLWARD-SADLER \\ From the Department of Pathology, Radcliffe Infirmary, Oxford
}

SYNOPSIS The features of four cases of malignant haemangioendothelioma involving the liver and other organs are described. Two cases were associated with a microangiopathic haemolytic $N$ anaemia. The nature of the tumours and possible pathogenesis for the anaemias are discussed.

Malignant haemangioendothelioma involving the liver is a rare tumour. Four cases have been seen at the Radcliffe Infirmary in the past 15 years. Two of them were associated with significant haematological abnormalities.

\section{Case Histories}

\section{CASE 1}

A 50-year-old woman was admitted to the Radcliffe Infirmary on 30 March 1959 (Radcliffe Infirmary registration number 181797) after passing several melaena stools. She had extensive bruises, but there were no other significant abnormalities on physical examination. The one-stage prothrombin time (Owren's) was $340 \mathrm{sec}$ (control $15 \mathrm{sec}$ ). The coagulation defect responded rapidly to parenteral administration of vitamin $K_{1}$ and there was no further melaena. Other investigations included: haemoglobin $10.2 \mathrm{~g} \%$, reticulocyte score $3.8 \%$, white cells $6300 / \mathrm{cmm}$, platelets $349000 / \mathrm{cmm}$.

Her past medical history included a right hemicolectomy in 1957 for a paracolic abscess involving the caecum. At laparotomy no tumour was found; the surface of the liver was noted to be bosselated, but no biopsy was taken.

In May 1959 the liver edge became palpable. Liver function tests, initially normal, deteriorated, the serum bilirubin rising to $2 \mathrm{mg} \%$ and the serum albumin falling to $2 \cdot 3 \mathrm{mg} \%$. The alkaline phosphatase remained normal and flocculation tests were negative throughout. At the end of May, the patient's condition deteriorated further, with loss of consciousness and development of a pulmonary infection, and she died on 2 June 1959.

${ }^{2}$ Present address: The Department of Pathology, University of Nottingham.

Received for publication 28 November 1973.
At necropsy (Radcliffe Infirmary pm number 449/59) the liver weighed $2470 \mathrm{~g}$ and showed a coarse cirrhosis in the lateral part of the right lobe. Cystic haemorrhagic lesions, many with an irregular honeycombed structure, were present throughout the rest of the liver; the lesions contained areas of $\not$ solid yellow thrombus and of fresh clot (fig 1). Similar lesions were present in the lumbar vertebrae, the upper end of the left femur, and in the right second, sixth, and seventh ribs; the ribs showed pathological fractures. The spleen weighed $186 \mathrm{~g}$ and contained no haemangiomatous lesions. Other findings included severe left lower lobe pneumonia and endometriosis in the ovaries.

\section{CASE 2}

An 84-year-old woman was admitted to the Radcliffe

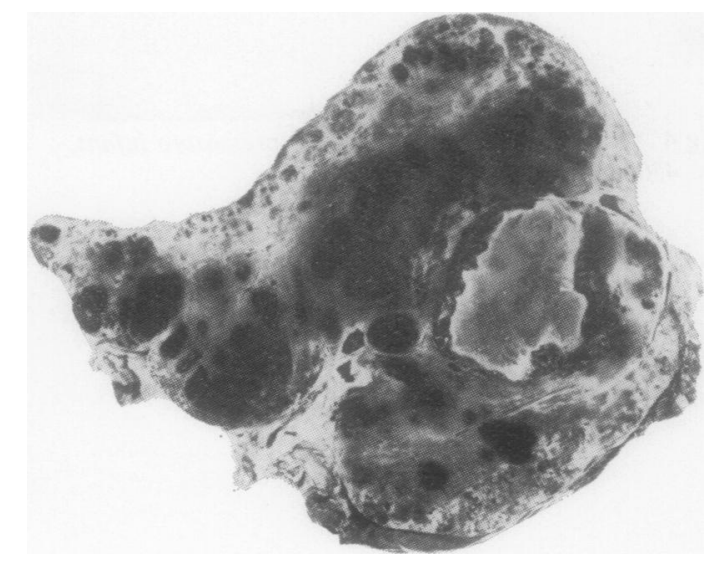

Fig 1 Case 1: cut surface of liver showing black nodules of tumour and a large yellow thrombus $(\times 1 / 5)$. 
Infirmary on 4 November 1970 (registration number 346085) with a six-month history of backache, nausea, left-sided abdominal pain, and swollen legs. On examination she was clinically anaemic and there was gross pitting oedema of the legs. A firm liver edge was palpable three fingerbreadths below the right costal margin. The spleen was enlarged to just below the umbilicus; it was firm with two nodules on its medial edge.

Investigations confirmed the anaemia ( $\mathrm{Hb} 8.8 \mathrm{~g} \%$ ) which was normochromic and normocytic. Burr cells and some fragmented cells were present. The reticulocyte score was $2.9 \%$ and there was moderate thrombocytopenia $(75000 / \mathrm{cmm})$. Bone marrow examination showed slight erythroid hyperplasia; megakaryocytes were present in normal numbers and were actively producing platelets. The reticulocyte score over the next two weeks varied from 2 to $4 \%$. Serum fibrin degradation products were measured on two occasions, and were 16 and $8 \mu \mathrm{g} / \mathrm{ml}$ (normal 2-8 $\mu \mathrm{g} / \mathrm{ml}$ ) The fibrinogen titre was normal at $1 / 128$. Coagulation times were within normal limits.

A liver and spleen scan showed that the liver was displaced by a mass in the left hypochondrium which did not take up the isotope. A laparotomy was performed on 30 November 1970 and a grossly enlarged spleen weighing $2400 \mathrm{~g}$ was removed (surgical histology number 11278/70) It consisted of a mass of haemangiomatous tissue and blood clot, with a narrow subcapsular zone of residual splenic tissue. There were haemorrhagic nodules in the liver, one of which was biopsied (surgical histology number 11278/70). Postoperatively thrombocytopenia persisted. The patient's condition deteriorated, with development of ascites, and a rising serum bilirubin, and she died on 6 January 1971.

At necropsy (pm number $31 / 71$ ) the peritoneal cavity contained 2 litres of serous fluid. The visceral and parietal peritoneum was studded with numerous minute black nodules up to $3 \mathrm{~mm}$ in diameter, which were cystic and contained blood. There was an abscess in the left hypochondrium. The liver weighed $2990 \mathrm{~g}$ and throughout its substance there were numerous circumscribed blue nodules, the largest $5 \mathrm{~cm}$ in diameter. There was no cirrhosis. The gallbladder contained multifaceted stones with black centres. The right adrenal gland weighed $40 \mathrm{~g}$ and was almost completely replaced by a haemangiomatous mass. The marrow cavities of the right humerus and femur were largely replaced by blueblack nodules, and there was a subcapital pathological fracture of the right humerus. Other findings included biventricular hypertrophy of the heart, inhalation of vomitus, and bronchopneumonia.
There was a brown granular tumour overlying the pituitary fossa.

\section{CASE 3}

A 69-year-old man was admitted to the Radcliffe Infirmary on 27 September 1971 (registration number 118716) with a history of general weakness and weight loss for more than a year, and epigastric pain for two months. He was found to be anaemic but was not jaundiced. The liver edge was palpable three fingerbreadths below the right costal margin and the spleen was just palpable.

Investigations showed a haemoglobin of $8.3 \mathrm{~g} \%$, a reticulocyte score of $5 \%$, and a platelet count of $45000 / \mathrm{cmm}$; the film showed fragmented red cells (fig 2). The blood picture was compatible with microangiopathic haemolytic anaemia. The fibrinogen titre was $1 / 64$ and the serum fibrin degradation products $48 \mu \mathrm{g} / \mathrm{ml}$.

A liver and spleen scan showed a bulky liver with no definite tumour deposits in it; there was no up-

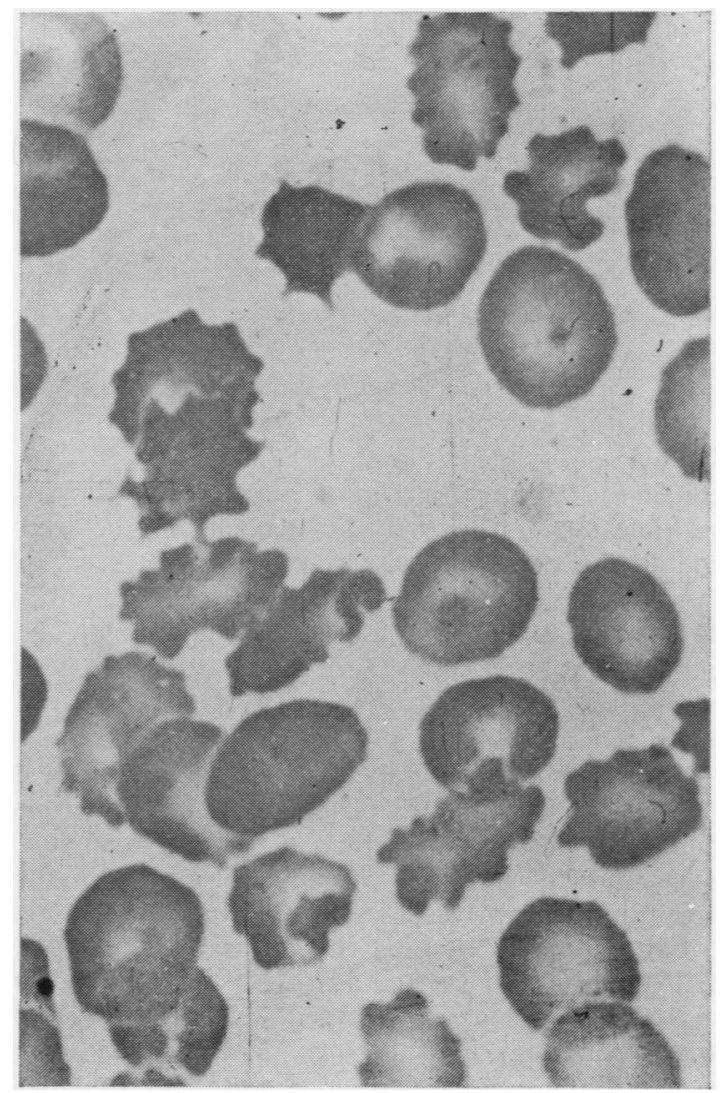

Fig 2 Case 3: peripheral blood film showing distorted and fragmented red cells $(\times 400)$. 


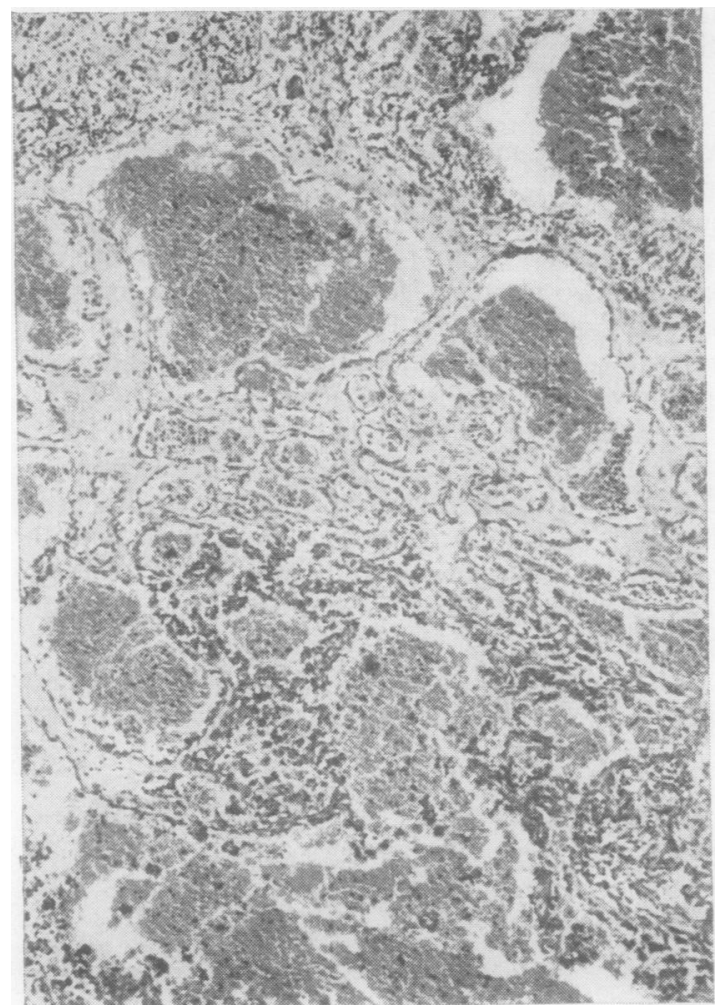

Fig 3

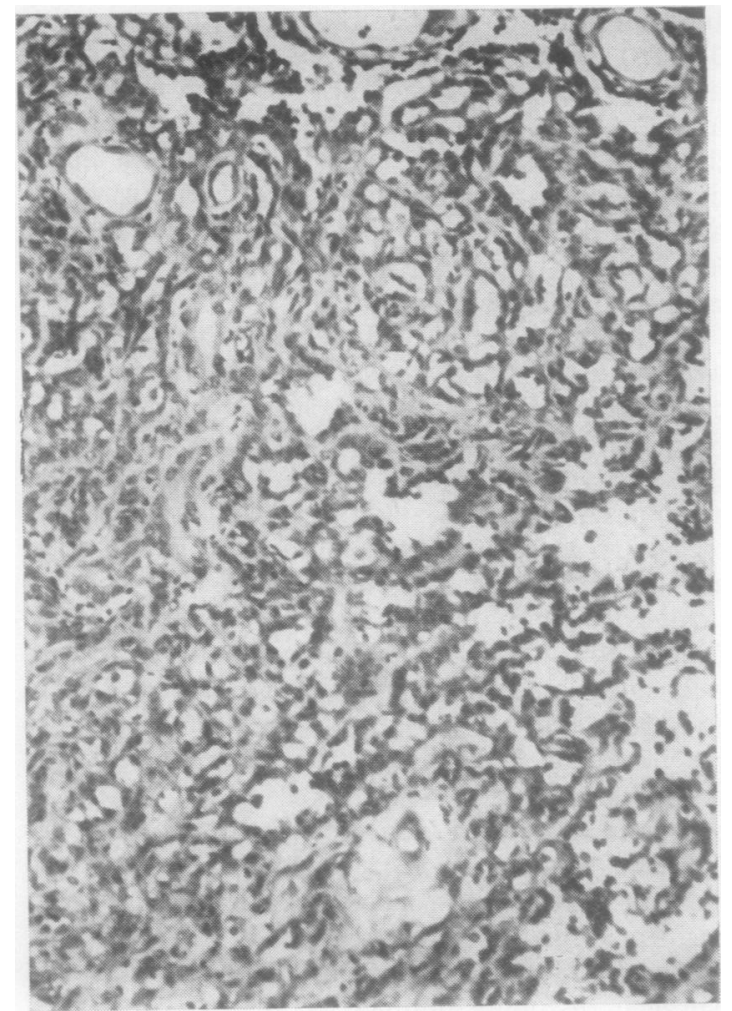

Fig 4

Fig 3 Case 3: low-power view of tumour nodule. Well formed blood-filled cystic spaces at the top and proliferation of tumour cells into similar spaces at the bottom $(\times 30)$.

Fig 4 Case 3: tumour lining irregular anastomosing vascular channels $(\times 102)$.

take in the left upper quadrant. Laparoscopy showed multiple small haemorrhagic deposits in the liver and in the omentum; the spleen was not seen. A liver biopsy was taken (surgical histology number 09955/71). As the tumour was inoperable, the patient was transfused and sent home. He was readmitted on 22 November 1971, anaemic and jaundiced, and died on 11 December 1971.

At necropsy (pm number 1304/71) the peritoneal cavity contained 2 litres of serous fluid. Numerous blue-black nodules, less than $0.5 \mathrm{~cm}$ in diameter, were studded over the parietal peritoneum, in the omentum, and in the mesentery. Some mesenteric lymph nodes contained haemorrhagic deposits. The liver weighed $3130 \mathrm{~g}$ and blue-black nodules, up to $5 \mathrm{~cm}$ in diameter, were present on the liver surface and throughout its substance. The nodules were filled with fluid blood and blood clot of varying age. The spleen weighed $1860 \mathrm{~g}$. Its pulp was replaced by nodules similar to those in the liver, the largest measuring $10 \mathrm{~cm}$ in diameter. The femoral shafts were filled with red marrow in which several shiny red areas of tumour were present. Tumour was also present in the sternum and lumbar vertebrae. Other findings included pulmonary oedema and diverticulosis of the sigmoid colon.

CASE 4

A 70-year-old man was admitted to the Radcliffe Infirmary on 8 September 1972 (registration number 60703) complaining of sharp, intermittent pain over the right lower ribs and right hypochondrium, especially on breathing deeply. He also had nausea, vomiting, and diarrhoea. There was no relevant past history. On examination he was obese, mildly febrile, slightly icteric, and had signs of congestive cardiac failure. No abnormal physical signs were detected in the abdomen. Investigations showed a biochemical picture typical of obstructive jaundice. There were no significant haematological abnor- 


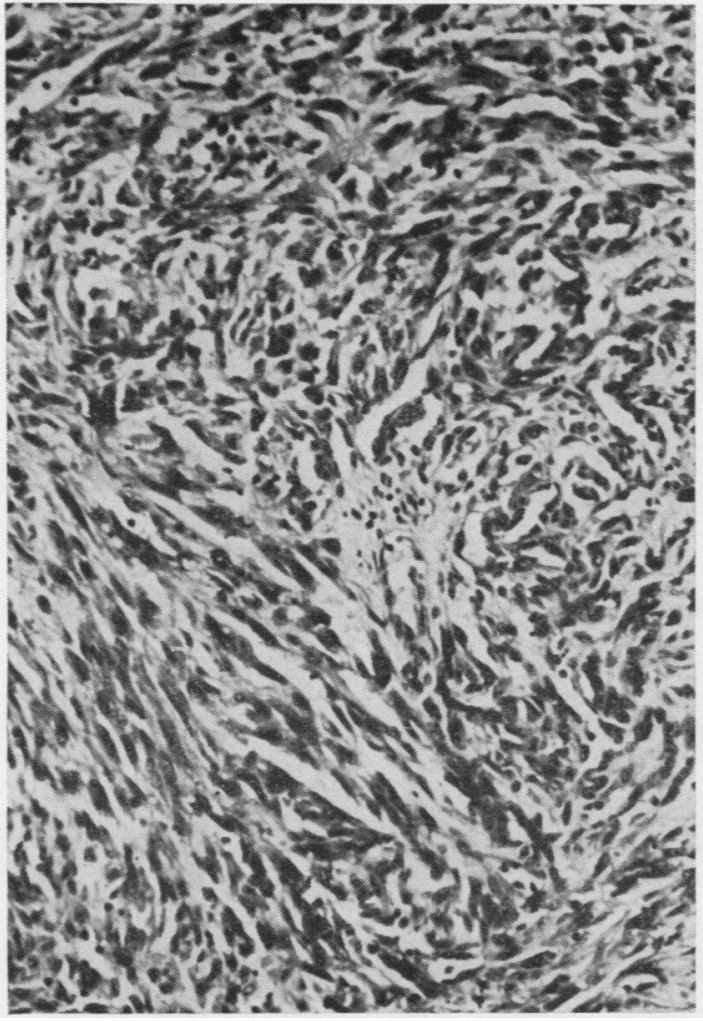

Fig 5

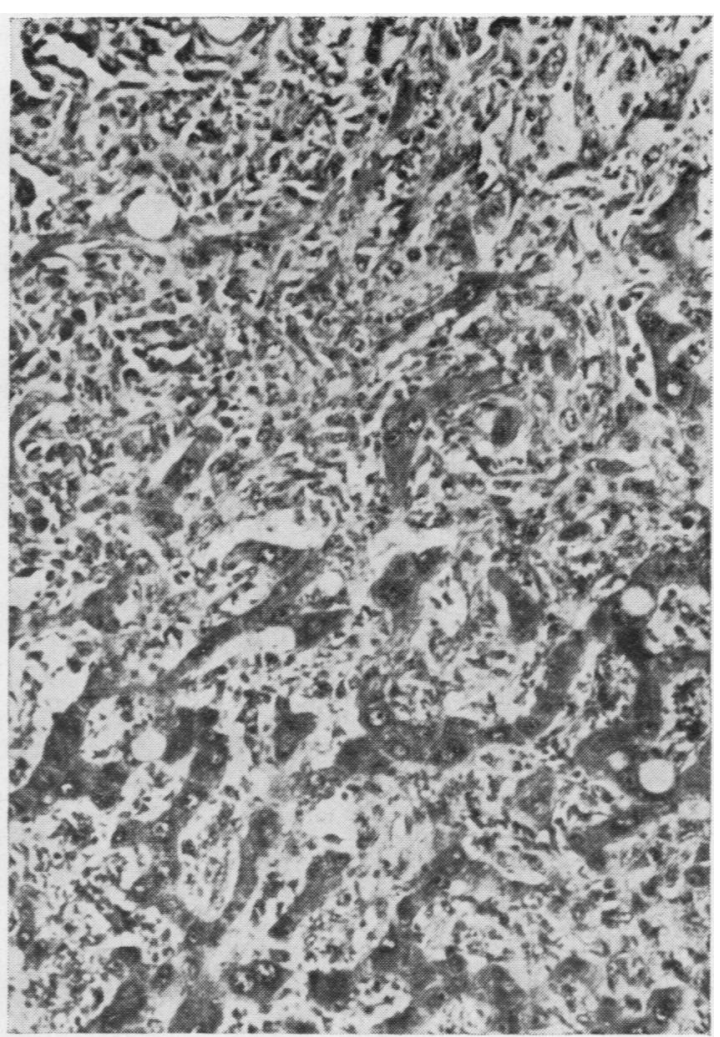

Fig 6

Fig 5 Case 2: spindle-cell area of tumour with poorly formed vascular spaces $(\times 102)$.

Fig 6 Case 4: infiltration of liver sinusoids by tumour with atrophy of hepatocytes $(\times 135)$.

malities. A cholecystogram showed that the gallbladder was not functioning. Laparotomy on 22 September 1972 revealed an enlarged liver with dark red nodular areas. The biliary system and pancreas appeared normal. A liver biopsy was taken (SH8793/72). The patient's condition gradually deteriorated; he became more jaundiced and signs of renal failure developed. He died on 2 October 1972.

At necropsy (pm number 1102/72) the liver weighed $2530 \mathrm{~g}$ and most of its substance was replaced by a nodular haemorrhagic black tumour, filled with thrombus in many areas. At some points the tumour had infiltrated into the jaundiced parenchyma. The spleen weighed $220 \mathrm{~g}$; it contained no tumour. Other findings included bilateral lower lobe consolidation of the lungs and early fibrinous pericarditis.

\section{Histology}

TUMOUR

The histological features of the tumour in all sites in these four cases are very similar. The tumour cells are pleomorphic, with large hyperchromatic nuclei. Mitoses are infrequent. Tumour giant cells are present in some areas. The tumour cells line irregular anastomosing vascular channels of varying size (figs 3 and 4): reticulin preparations show proliferation of tumour cells within the reticulin framework of the channels. In the liver there are areas in which tumour cells surround groups of hepatic parenchymal cells, which then appear to be lying free within the vascular spaces. In some tumour nodules the cells are elongated and spindle-shaped and vascular channels are prominent (fig 5). At the edges of the tumour nodules the tumour cells infiltrate extensively along hepatic sinusoids (fig 6). Invasion of a portal venous radicle by tumour is demonstrable in case 4 . Within the vascular channels of the tumour there are thrombi of varying ages and small haemopoietic foci. The degree of differentiation of the tumour varies in different nodules. In some, the vascular channels are lined by a single layer of plump endothelial cells and the appearances resemble 


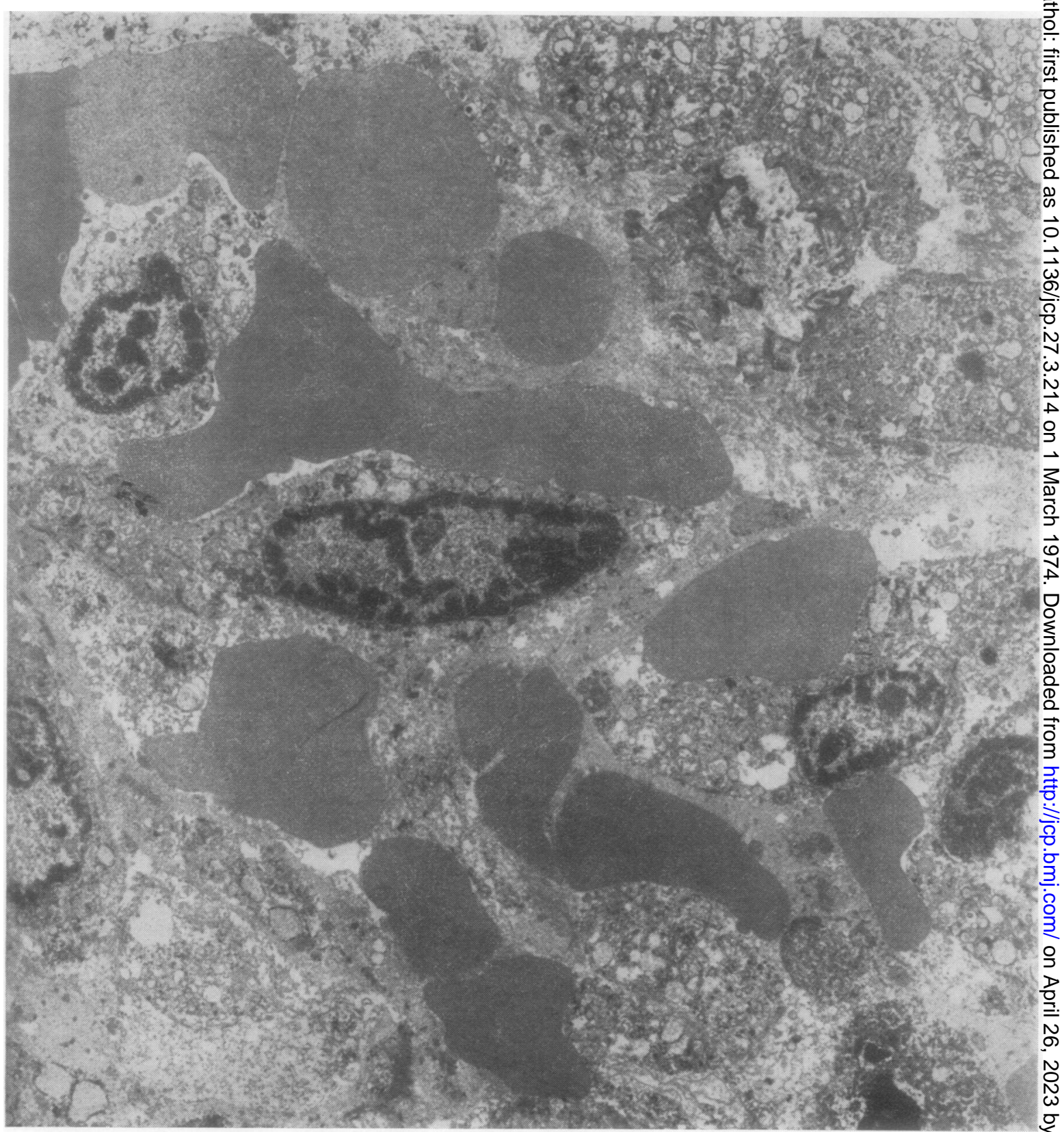

Fig 7 Case 4: electron micrograph of tumour cells in intimate contact with erythrocytes. Cytoplasmic projection from tumour cell into vascular channels $(\times 6000)$.

a cavernous haemangioma. This was the case in the liver biopsy from case 2 . At the other end of the spectrum are nodules in which the cells are very bizarre and form polypoid masses projecting into the vascular spaces (fig 3).
No definite phagocytosis of pigment or of erythrocytes by tumour cells has been demonstrated. However, in some areas the tumour cells show a reticular pattern in which there are single red cells surrounded by a clear space. Since the tumour cell boundaries 
are ill defined, it is difficult to know whether this appearance represents erythrophagocytosis, or whether the tumour cells are forming a fine meshwork of minute vascular channels; the latter is thought more probable.

In case 4 electron microscopy of postmortem material demonstrates tumour cells projecting into the vascular channels, and in intimate contact with erythrocytes. Despite severe postmortem autolysis, cytoplasmic projections from the tumour cells are still evident (fig 7). There is no evidence of phagocytosis by tumour cells.

\section{LIVER}

The remaining liver is cirrhotic only in case 1 , the cirrhosis being macronodular in type. There is no histological indication of its aetiology. The other three cases show some degree of portal fibrosis in areas remote from tumour tissue. In all cases, considerable amounts of haemosiderin are present in Kupffer cells, especially in areas adjacent to tumour nodules, but parenchymal siderosis is present only in case 3. There is generalized Kupffer cell hyperplasia. In cases 2 and 3 erythrophagocytosis by hyperplastic Kupffer cells is demonstrable (fig 8) and there are haemopoietic foci in hepatic sinusoids.

\section{Other Relevant Histological Findings}

\section{CASE 1}

Sections of the brain show increased numbers of Alzheimer type II cells in the globus pallidus, suggesting hepatic encephalopathy.

\section{CASE 2}

There are thrombi in arterioles and capillaries in the lungs and kidneys. The renal tubular cells contain iron demonstrated by Perl's Prussian Blue reaction. Some tubules contain red cells, indicating that there was haematuria. The tumour near the pituitary proved to be a meningioma.

\section{CASE 3}

Appropriate histochemical tests demonstrated iron in renal tubular cells. No thrombi were present except within the tumour.

\section{Discussion}

The mode of presentation of patients with haemangioendothelioma of the liver is variable. Common features of the clinical history in patients with this tumour are a short illness with a rapid downhill course, jaundice of late onset, and death in hepatic coma (Baker, Paget, and Dawson, 1956). Two of our cases presented with the effects of hepatospleno-

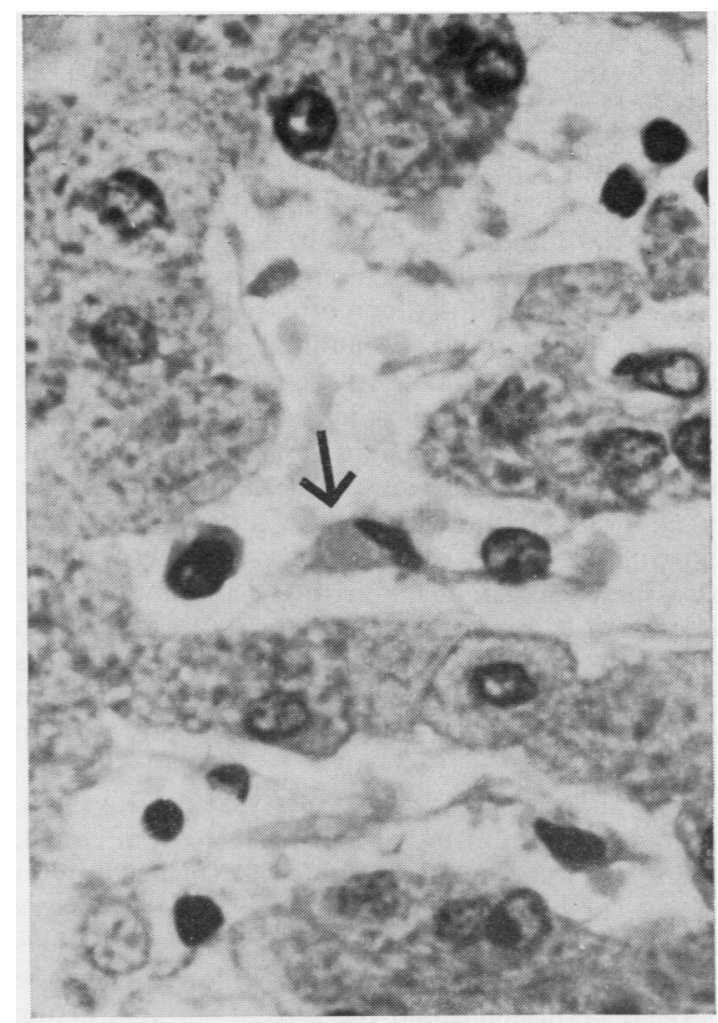

Fig 8 Case 2: erythrophagocytosis by a Kupffer cell (arrow) is non-neoplastic liver $(\times 198)$.

megaly; in both these cases the spleen as well as the liver was involved by the tumour. One case presented with obstructive jaundice for which no extrahepatic cause was found. The remaining patient presented with a bleeding diathesis attributable to cirrhosis. The tumour was unsuspected during life.

Diagnosis of these tumours can be difficult. At laparoscopy or laparotomy they appear as haemorrhagic nodules. Histologically haemangioendothelioma must be distinguished from other vascular and vasoformative tumours. The liver biopsy from case 2 was diagnosed as an angioma despite a concomitant diagnosis of a haemangioendothelioma of the spleen. At necropsy some other nodules had a similar appearance, though most were clearly malignant; intermediate grades could also be seen. This variation may represent varying degrees of differentiation of the tumour although preexisting benign haemangiomata cannot be excluded. Malignant transformation of such preexisting lesions has been suggested as a mode of origin (Hastings-James, 1949).

We have preferred to call these tumours haeman- 
gioendotheliomata, although similar tumours in the liver have also been designated as Kupffer cell sarcomas (Ogilvie and Mackenzie, 1936; Burston, 1958; Edmondson, 1958), reflecting the belief of these authors in an origin from this cell type. In all our cases the histology is similar, but whereas in case 4 the tumour only involved the liver even at necropsy, in two other patients the spleen showed major involvement and could represent the primary tumour. Furthermore haemopoietic foci were seen within and in intimate association with tumour deposits; this may reflect the haemopoietic potential of sinusoidal endothelium and is a common, possibly invariable, feature of these tumours (Baker et al, 1956). Although we have noted Kupffer cell hyperplasia elsewhere in the liver we interpret this as a mesenchymal reaction to the tumour with its associated thrombosis and necrosis. We have been unable to find any good evidence of phagocytosis by tumour cells either on light microscopy or, in case 4 , on electron microscopy of postmortem material.

The tumour spreads by direct vascular invasion, as could be demonstrated in a portal vein of case 4, and also by the coelomic route. At splenectomy in case 2, only involvement of spleen and liver was noted, and yet by the time the patient died, 37 days later, numerous small tumour nodules studded the parietal peritoneum and the serosal surfaces of the mesentery, small bowel, and colon. Although pulmonary metastases have been demonstrated in up to $50 \%$ of cases (Edmondson, 1958) none were found in any of ours, which is surprising considering the extensive bone marrow involvement in three patients.

A few aetiological factors are recognized. An association with Thorotrast (Da Silva Horta, 1956; Grampa, 1971) and chronic arsenic intoxication (Regelson, Kim, Ospina, and Holland, 1968) has been described on various occasions, and in about $40 \%$ of cases the liver was also cirrhotic (quoted by MacSween, Vetters, Ross, Ferguson, Johnstone, and Sandison, 1972). One case has followed prolonged exposure to gamma rays (Ross, 1932) and two cases are described in association with idiopathic haemochromatosis (Kwittken and Tartow, 1966). In one of our cases there was a cirrhosis, but no other aetiological factor has been identified.

Microangiopathic haemolytic anaemia complicates various disease states, including carcinomatosis, and has been described in several adults with haemangioendotheliomas of the liver (Alpert and Benisch, 1970; Donald and Dawson, 1971; Hopfner Dufour, Pluot et al, 1972). Two of our four cases had evidence of a haemolytic anaemia, and the distorted and fragmented red cells in the blood films suggested that the haemolysis was related to a microangiopathic process. The red cell damage is thought to be caused by mechanical trauma to erythrocytes as they pass through a fibrin meshwork in small blood vessels (Brain, Dacie, and Hourihane, 1962; Bull, Rubenberg, Dacie, and Brain, 1968) and the damaged cells are more susceptible to uptake by the reticuloendothelial system. Evidence supporting this has recently been obtained by scanning electron microscopic examination of transplanted subcutaneous haemangioendotheliomas in mice (Warner, Hoak, and Fry, 1971). This study suggests formation of a fibrin meshwork before erythrocyte damage, while our electron microscopy in case 4 suggests that the intimate relationship of erythrocytes to tumour cells may also be an important factor. The red cell damage could be a contributory stimulus to the generalized Kupffer cell hyperplasia frequently seen, as indicated by the demonstrable erythrophagocytosis in our two cases and in those of Alpert and Benisch. It may be pertinent that this anaemia occurred in the two patients with massive splenic involvement; this association was also seen in two of Alpert and Benisch's series and in the case of Donald and Dawson. Not only may the increased tumour mass contribute to the anaemia, but loss of splenic function may help to 'expose' the nature of the haemolytic process.

Thrombocytopenia in association with various vascular tumours has often been described, usually in infancy and childhood (Kasabach and Merritt, 1940, Gilon, Ramot, and Sheba, 1959; Blix and Aas, 1961; Gibbs, Connor, and Hutchison, 1966; Silver, Aggeler, and Crane, 1948). A chronic consumption coagulopathy within the tumour is now regarded as the usual mechanism for, the thrombocytopenia (Gilon et al, 1959; Good, Carnazzo, and Good, 1955; Kontras, Green, King, and Duran, 1963; Shanberge, Tanaka, and Gruhl, 1971). This appeared to be true in our case 3. Histological evidence for more widespread intravascular coagulation is uncommon, but was found in our second case.

We should like to thank $\mathrm{Mr}$ Till and $\mathrm{Mr}$ Moloney for access to the clinical notes, Dr A. H. T. Robb-Smith for his helpful advice and encouragement, Dr P. M. Emerson for her help, Dr T. M. Parry and Mr D. Luckett for the time they spent on the photography, Mr A. J. Chaplin for his technical assistance, and $\mathrm{Mr} \mathrm{D}$. Jerome for the electron microscopic preparations.

\section{References}

Alpert, L. I., and Benisch, B. (1970). Hemangioendothelioma of the liver associated with microangiopathic hemolytic anemia. Amer. J. Med., 48, 624-628. 
Baker, H., de C., Paget, G. E., and Davson, J. (1956). Haemangioendothelioma (Kupffer-cell sarcoma) of the liver. J. Path. Bact., 72, 173-182.

Blix, S., and Aaas, K. (1961). Giont haemangioma, thrombocytopenia, fibrinogenopenia, and fibrinolytic activity. Acta med. scand., 169, 63-70.

Brain, M. C., Dacie, J. V., Hourihane, D. O'B. (1962). Microangiopathic haemolytic anaemia; the possible role of vascular lesions in pathogenesis. Brit. J. Haemat., 8, 358-374.

Bull, B. S., Rubenberg, M. L., Dacie, J. V., Brain, M. C. (1968). Microangiopathic haemolytic anaemia: mechanisms of red cell fragmentation: in vitro studies. Brit. J. Haemat., 14, 643-65?.

Burston, J. (1958). Kupffer cell sarcoma. Cancer (Philad.), 11, 798-802.

Da Silva Horta, J. (1965). Late lesions in man caused by colloidal thorium dioxide (Thorotrast): a new case of sarcoma of the liver twenty-two years after the injection. Arch. Path., 62, 403-418.

Donald, D., and Dawson, A. A. (1971). Microangiopathic haemolytic anaemia associated with malignant haemangio-endothelioma. J. clin. Path., 24, 456-459.

Edmondson, H. A. (1958). Haemangioendothelial sarcoma. In Tumors of the Liver and Intrahepatic Bile Ducts (Atlas of Tumor Pathology, Sect, VII, fasc. 25), pp. 139-145. Armed Forces Institute of Pathology, Washington, D.C.

Gibbs, W. N., Connor, R. C. R., and Hutchison, H. E. (1966). Malignant haemangio-endothelioma associated with thrombocytopenia. J. Path. Bact., 92, 207-210.

Gilon, E., Ramot, B., and Sheba, C. (1959). Multiple hemangiomata associated with thrombocytopenia: remarks on the pathogenesis of the thrombocytopenia in this syndrome. Blood, 14, 74-79.

Good, T. A., Carnazzo, S. F., and Good, R. A. (1955). Thrombocytopenia and giant hemangioma in infants. Amer. J. Dis. Child., 90, 260-274.

Grampa, G. (1971). Radiation injury with particular reference to Thorotrast. Path. Ann., 6, 147-169.

Hastings-James, R. (1949). Malignant haemangio-endothelioma (haemangioblastoma), of the liver. J. Path. Bact., 61, 49-53.

Hopfner, C., Dufour, M., Pluot, M., et al (1972). Hémangioendothelio-sarcome splénique avec erythrophagocytose et angiopathie thrombotique. Etude morphologique, optique et ultrastructurale. Virchows Arch. path, Anat., 356, 66-75.

Kasabach, H. H., and Merritt, K. (1940). Capillary hemangioma with extensive purpura: report of a case. Amer. J. Dis. Child., 59, 1063-1070.

Kontras, S. B., Green, O. C., King, L., and Duran, R. J. (1963). Giant hemangioma with thrombocytopenia: case report with survival and sequestration studies of platelets labeled with chromium 51. Amer. J. Dis. Child., 105, 188-195.

Kwittken, J., and Tartow, L. R. (1966). Haemochromatosis and Kupffer-cell sarcoma with unusual localisation of iron. J. Path. Bact., 92, 571-573.

MacSween, R. N. M., Vetters, J. M., Ross, S. K., Ferguson, J. M., Johnstone, J. M., and Sandison, A. T. (1972). Haemangioendothelial sarcoma of the liver. J. Path., 109, 39-44.

Ogilvie, R. F., and Mackenzie, I. (1936). Malignant haemangioendothelioma, with a report of two cases. J. Path. Bact., 43, 143-150, 429-430.

Regelson, W., Kim, U., Ospina, J., and Holland, J. F. (1968). Hemangioendothelial sarcoma of liver from chronic arsenic intoxication by Fowler's solution. Cancer (Philad.), 21, 514-522.

Ross, J. M. (1932). A case illustrating the effects of prolonged action of radium. J. Path. Bact., 35, 899-912.

Shanberge, J .N., Tanaka, K., and Gruhl, M. C. (1971). Chronic consumption coagulopathy due to hemangiomatous transformation of the spleen. Amer. J. clin. Path., 56, 723-729.

Silver, H. K., Aggeler, P. M., and Crane, J. T. (1948). Hemangioma (capillary and cavernous) with thrombocytopenic purpura: report of a case with observations at autopsy. Amer. J. Dis. Child., 76, 513-520.

Warner, E. D., Hoak, J. C., and Fry, G. L. (1971). Hemangioma, thrombocytopenia and anemia: the Kasabach-Merritt syndrome in an animal model. Arch. Path., 91, 523-528. 